\title{
Quality of life after transcatheter aortic valve implantation and surgical replacement in high-risk elderly patients
}

\author{
Petr Kalaa , Martin Tretina ${ }^{b}$, Martin Poloczek ${ }^{\mathrm{a}}$, Jiri Ondrasek ${ }^{\mathrm{b}}$, Petr Malik ${ }^{\mathrm{b}}$, Petr Pokorny' ${ }^{\mathrm{b}}$, Jiri Parenica ${ }^{\mathrm{a}}$, Jindrich Spinara ${ }^{\mathrm{a}}$ \\ Jiri Jarkovsky', Simona Littnerovac, Petr Nemec ${ }^{\mathrm{b}, \mathrm{d}}$
}

\begin{abstract}
Aim. The aim of this study was to compare the quality of life after transcatheter aortic valve implantation (TAVI) and surgical replacement (SAVR) at one year.

Methods. The study included 45 consecutive high-risk patients (average age 82.0 years; logistic Euroscore 22.3\%) with symptomatic severe aortic stenosis allocated to TAVI transfemoral, TAVI transapical using the Edwards-Sapien valve or SAVR with the Edwards Perimount bioprosthesis ( $n=15$ in each). The pre-operative characteristics were similar except for more myocardial infarctions in TAVI. The quality of life was assessed using the standardized EQ-5D questionnaire at baseline and on days 30,90 and 360. The protocol was approved by the local ethics committee and an informed consent was signed. A total of 7 patients (15.5\%) died during follow-up.

Results. At baseline no significant differences in any of the quality-of-life parameters were found except for usual activities described as "best" ( $46.7 \%$ in SAVR vs. $10.0 \%$ in TAVl; $P=0.002$ ). At 30 and 90 days surviving patients were similar and at 360 days only the anxiety/depression score was "best" in $83.3 \%$ SAVR vs. $59.1 \%(P=0.046)$. Functional status improved in all patients (NYHA class I-II in $13.3 \%$ at baseline vs. $78.9 \%$ at 360 -days) and the general health median significantly improved in TAVI patients (from 50 to $67 ; P=0.001$ ) with a positive trend in SAVR patients $(P=0.060)$.

Conclusions. At one year, the general quality of life of high-risk patients had significantly improved after transcatheter aortic valve implantation with a positive trend in surgically treated patients.
\end{abstract}

Key words: quality of life, EQ-5D, aortic replacement , aortic valve implantation, TAVI, bioprosthesis

Received: February 27, 2012; Accepted: June 11, 2012; Available online: September 5, 2012

http://dx.doi.org/10.5507/bp.2012.062

${ }^{a}$ Department of Internal Cardiology Medicine LF MU and FN Brno, Czech Republic

${ }^{b}$ Center of Cardiovascular Surgery and Transplantations, Brno

'Institute of Biostatistics and Analyses MU, Brno

'International Clinical Research Center, Brno

Corresponding author: Petr Nemec, email: petr.nemec@cktch.cz

\section{INTRODUCTION}

Surgical aortic valve replacement (SAVR) was, until recently, the only effective therapeutic option for patients with symptomatic aortic stenosis. Unfortunately one third of patients did not receive this treatment mainly because of advanced age or severe co-morbidities ${ }^{1}$. The main negative prognostic factors linked to short-term postoperative mortality were quantitatively determined from the logistic EuroScore which has been recently updated in the EuroScore II (www.euroscore.org) (ref. ${ }^{2}$ ). However, even the new scoring system is unable to capture the complete risk of patients, for instance those with poor mental status, contraindication for general anesthesia, or extracorporeal circulation. In the PARTNER trial it was shown that patients who were not indicated for SAVR benefited from transcatheter aortic valve implantation (TAVI) $\left(\right.$ ref. $\left.^{3}\right)$. The balloon-expandable Sapien valve (Edwards Lifesciences, Inc., Irvine, California, United States) can be used for TAVI delivered through the transfemoral (TF) or transapical (TA) approach ${ }^{4}$, additionally, the self-expanding CoreValve system (Medtronic-CorevalveTM, LLC; Minneapolis, Minnesota, United States) is also commer- cially available. The aim of this study was to ascertain the quality of life of TAVI patients in the initial phase of the program directly compared with SAVR patients as the well-established method in the same center. When dealing with the elderly population at very high risk, the quality of life should be at least as important as survival ${ }^{5}$.

\section{MATERIALS AND METHODS}

The single-center observational study included 45 consecutive high-risk patients (average age $82.0 \pm 4.5$ years; logistic EuroSCORE $22.3 \pm 7.6$; diabetes mellitus $42.2 \%$ ) with symptomatic severe aortic stenosis indicated for aortic valve intervention from June 2009 to December 2010 (68.9\% were women). Patients age > 75 years with a logistic Euroscore > $15 \%$ were divided into one of three groups according to the type of procedure: TAVI transfemoral (TF-TAVI) $(\mathrm{n}=15)$, TAVI transapical (TA-TAVI) $(n=15)$ or SAVR $(n=15)$. All procedures were performed under general anesthesia and in cases of TFTAVI a common femoral artery was surgically disected. The pre-operative characteristics were similar except for 
more frequent myocardial infarctions in the TAVI groups. The Edwards Sapien valve was implanted in the TAVI patients and Edwards Perimount bioprosthesis was used in the SAVR patients. The logistic Euroscore was significantly higher in the TAVI groups than in the SAVR group ( 18 vs. $24 ; P=0.025$ ). The selection of patients was approved by the multidisciplinary heart-team according to the recommendation of Vahanian et al. ${ }^{6}$ and all the characteristics, treatments and results are described in detail in a previous publication ${ }^{7}$. In summary, patients with a bicuspid aortic valve, ischemic heart disease requiring revascularization after the aortic valve intervention, severely impaired left ventricular ejection fraction and mitral or aortic regurgitation were contraindicated for the procedures. Also, patients with serious co-morbidities and an estimated life expectancy of less than three years were not enrolled. The patients were followed according to the protocol approved by the local ethics committee. All patients signed an informed consent before baseline investigations and the study was conducted in accordance with the Helsinki declaration. In addition to the more exact clinical, echocardiographic and CT angiographic parameters, we also measured subjective health status attributable to treatment. The quality of life was assessed using a self-administered standardized EuroQol EQ-5D questionnaire $^{8}$ describing mobility, self-care, usual activities, pain/discomfort, anxiety/depression and general health at baseline (D0), 30-days (D30), 90-days (D90) and 360-days (D360). Each dimension had three levels reflecting health problems as none - moderate - extreme. The current general health was determined by a mark placed on a 20-centimeter visual analog scale. Analysis was done in the "intention-to-treat" manner and all the EQ-5D data from baseline through the 1-year follow-up were obtained from 33 patients. The EQ-5D questionnaire was used with permission of the EuroQol Group.

\section{Statistical analysis}

Standard descriptive statistics were applied in the analysis. Quantitative variables were described using means and standard deviation or median supplemented by $5^{\text {th }}-$ $95^{\text {th }}$ percentile range; categorical variables were described as absolute and relative frequencies. Direct comparison among groups was set up using the ML-Chi-square test for categorical variables and Mann-Whitney U test for quantitative variables. Changes in the EQ-5D dimensions between baseline and 1-year follow-up were analyzed using the Wilcoxon test. The level of statistical significance was set at $\alpha=0.05$. All analyses were carried out with the software SPSS 19.0.1 (IBM Corporation, 2010).

\section{RESULTS}

The main clinical, echocardiographic and laboratory results were described previously ${ }^{7}$. Because of the obvious association between the objective and subjective parameters of health, it is necessary to briefly mention the results. All patients in all groups were treated successfully with either TAVI or SAVR. One patient suffered an iliac rupture at the end of the TF-TAVI, which was immediately surgically corrected in the hybrid operating theatre. Three patients had repeat procedures (1 SAVR and 2 TA-TAVI). There were several other complications, e.g. renal failure in six patients, respiratory failure in six patients and neurological complications in four patients. The functional status after the procedure and follow-up was significantly improved for the total group of surviving patients (New York Heart Association [NYHA] class I-II in $13.3 \%$ at baseline vs. $78.9 \%$ at 360 -days and at the same time NYHA class IV decreased from $22.2 \%$ to $0 \%$ ). All procedures were technically successful, 2 patients $(4.4 \%)$ died during the 30-day or prolonged hospital stay and another 5 patients (11.1\%) died during the 1-year follow-up.

The prognostic impact of the objective parameters and complications defined in the VARC (Valvular Academic Research Consortium) (ref. ${ }^{9}$ ) are under investigation and will be published separately.

1. Comparison of TAVI vs. SAVR: At baseline no significant differences in overall quality-of-life parameters were found among groups except for usual activities described as "best" (46.7\% in SAVR vs. $10.0 \%$ in TAVI; $P=0.002$ ). At 30 and 90 days the surviving patients reported a similar health status. At 360 days, only the anxiety/depression score described as "best" was found more often in SAVR patients ( $83.3 \%$ vs. $59.1 \% ; P=0.046)$. General health significantly improved only in TAVI patients $(P=0.001)$; however, there was a positive trend found in SAVR patients $(P=0.060)$. (Table 1 )

2. Comparison of TF-TAVI vs TA-TAVI vs SAVR: Very similar results in the quality of life assessment were found if the analysis was also focused on the type of TAVI approach. We observed one exception regarding the general health feeling of patients at 90 days. Patients treated with the TF-TAVI scored lower than SAVR patients but this difference had disappeared at one year. No differences were found between TF- and TA-TAVI patients over the course of the study. (Table 2)

\section{DISCUSSION}

Our study focused on the quality of life (QoL) assessed by the standardized EQ-5D three level questionnaire in patients treated using the classical surgical approach (SAVR) compared with patients treated with TAVI. The general quality of life as well as all physical dimensions and NYHA functional status were similar at baseline but significantly improved one year after TAVI (general QoL 50 vs. 67 points for TAVI; NYHA III-IV in 86.6\% vs. $21 \%$ in the whole group). These results correspond well with the results of Georgiadou et al. using the Medical Outcomes Study (MOS) Short Form 36 (SF-36) tool and its shorter alternative SF-12 version 2 (SF-12v2) health survey in 40 TAVI patients treated with the CoreValve system $^{10}$. Similar results in patients aged $\geq 81$ were found by Bekeredjian et al. ${ }^{11}$ at 6 months. The greatest improvement was observed in physical functioning (23.4 vs. 67.8; $P<0.001)$. Very recently the QoL in 358 inoperable patients were analyzed by Reynolds et al. as a preplanned 
Table 1. Comparison of quality of life between patients treated with surgical (SAVR) and transcatheter (TAVI) aortic valve implantation up to 1 year.

\begin{tabular}{|c|c|c|c|c|c|}
\hline Dimensions & Levels & $\begin{array}{l}\text { Total }^{1} \\
\mathrm{~N}=45\end{array}$ & $\begin{array}{l}\text { SAVR }^{1} \\
\mathrm{~N}=15\end{array}$ & $\begin{array}{c}\text { TF+TA TAVI }{ }^{1} \\
\text { N=30 }\end{array}$ & $P^{2}$ \\
\hline \multicolumn{6}{|l|}{$E Q-5 D D 0$} \\
\hline$\%$ General QoL & & $50(20 ; 80)$ & $55(20 ; 80)$ & $50(20 ; 80)$ & 0.348 \\
\hline \multirow{4}{*}{ mobility } & excellent & $13(28.9 \%)$ & $6(40.0 \%)$ & $7(23.3 \%)$ & 0.332 \\
\hline & moderate & $29(64.4 \%)$ & $9(60.0 \%)$ & $20(66.7 \%)$ & \\
\hline & low & $2(4.4 \%)$ & $0(0.0 \%)$ & $2(6.7 \%)$ & \\
\hline & NA & $1(2.2 \%)$ & $0(0.0 \%)$ & $1(3.3 \%)$ & \\
\hline \multirow[t]{3}{*}{ self-care } & excellent & $31(68.9 \%)$ & $12(80.0 \%)$ & $19(63.3 \%)$ & 0.222 \\
\hline & moderate & $11(24.4 \%)$ & $3(20.0 \%)$ & $8(26.7 \%)$ & \\
\hline & low & $3(6.7 \%)$ & $0(0.0 \%)$ & $3(10.0 \%)$ & \\
\hline \multirow[t]{3}{*}{ usual activities } & excellent & $10(22.2 \%)$ & $7(46.7 \%)$ & $3(10.0 \%)$ & $0.002 *$ \\
\hline & moderate & $27(60.0 \%)$ & $8(53.3 \%)$ & $19(63.3 \%)$ & \\
\hline & low & $8(17.8 \%)$ & $0(0.0 \%)$ & $8(26.7 \%)$ & \\
\hline \multirow[t]{3}{*}{ pain/discomfort } & excellent & $11(24.4 \%)$ & $6(40.0 \%)$ & $5(16.7 \%)$ & 0.136 \\
\hline & moderate & $30(66.7 \%)$ & $7(46.7 \%)$ & $23(76.7 \%)$ & \\
\hline & low & $4(8.9 \%)$ & $2(13.3 \%)$ & $2(6.7 \%)$ & \\
\hline \multirow[t]{2}{*}{ anxiety/depression } & excellent & $30(66.7 \%)$ & $12(80.0 \%)$ & $18(60.0 \%)$ & 0.169 \\
\hline & moderate & $15(33.3 \%)$ & $3(20.0 \%)$ & $12(40.0 \%)$ & \\
\hline \multicolumn{6}{|l|}{$E Q-5 D$ D30 } \\
\hline$\%$ General QoL & & $58(40 ; 80)$ & $50(30 ; 80)$ & $60(43 ; 80)$ & 0.419 \\
\hline \multirow[t]{2}{*}{ mobility } & excellent & $5(15.6 \%)$ & $3(33.3 \%)$ & $2(8.7 \%)$ & 0.101 \\
\hline & moderate & $27(84.4 \%)$ & $6(66.7 \%)$ & $21(91.3 \%)$ & \\
\hline \multirow[t]{3}{*}{ self-care } & excellent & $17(53.1 \%)$ & $5(55.6 \%)$ & $12(52.2 \%)$ & 0.222 \\
\hline & moderate & $11(34.4 \%)$ & $4(44.4 \%)$ & $7(30.4 \%)$ & \\
\hline & low & $4(12.5 \%)$ & $0(0.0 \%)$ & $4(17.4 \%)$ & \\
\hline \multirow[t]{3}{*}{ usual activities } & excellent & $14(43.8 \%)$ & $5(55.6 \%)$ & $9(39.1 \%)$ & 0.681 \\
\hline & moderate & $10(31.3 \%)$ & $2(22.2 \%)$ & $8(34.8 \%)$ & \\
\hline & low & $8(25.0 \%)$ & $2(22.2 \%)$ & $6(26.1 \%)$ & \\
\hline \multirow[t]{2}{*}{ pain/discomfort } & excellent & $14(43.8 \%)$ & $6(66.7 \%)$ & $8(34.8 \%)$ & 0.101 \\
\hline & moderate & $18(56.3 \%)$ & $3(33.3 \%)$ & $15(65.2 \%)$ & \\
\hline \multirow{2}{*}{ anxiety/depression } & excellent & $20(62.5 \%)$ & $4(44.4 \%)$ & $16(69.6 \%)$ & 0.191 \\
\hline & moderate & $12(37.5 \%)$ & $5(55.6 \%)$ & $7(30.4 \%)$ & \\
\hline \multicolumn{6}{|l|}{$E Q-5 D D 90$} \\
\hline$\%$ General QoL & & $65(40 ; 85)$ & $75(50 ; 85)$ & $63(40 ; 80)$ & 0.084 \\
\hline \multirow[t]{2}{*}{ mobility } & excellent & $10(27.8 \%)$ & $4(50.0 \%)$ & $6(21.4 \%)$ & 0.125 \\
\hline & moderate & $26(72.2 \%)$ & $4(50.0 \%)$ & $22(78.6 \%)$ & \\
\hline self-care & excellent & $23(63.9 \%)$ & $6(75.0 \%)$ & $17(60.7 \%)$ & 0.630 \\
\hline & moderate & $12(33.3 \%)$ & $2(25.0 \%)$ & $10(35.7 \%)$ & \\
\hline & low & $1(2.8 \%)$ & $0(0.0 \%)$ & $1(3.6 \%)$ & \\
\hline usual activities & excellent & $11(30.6 \%)$ & $4(50.0 \%)$ & $7(25.0 \%)$ & 0.157 \\
\hline & moderate & $20(55.6 \%)$ & $4(50.0 \%)$ & $16(57.1 \%)$ & \\
\hline & low & $5(13.9 \%)$ & $0(0.0 \%)$ & $5(17.9 \%)$ & \\
\hline pain/discomfort & excellent & $16(44.4 \%)$ & $3(37.5 \%)$ & $13(46.4 \%)$ & 0.672 \\
\hline & moderate & $19(52.8 \%)$ & $5(62.5 \%)$ & $14(50.0 \%)$ & \\
\hline & low & $1(2.8 \%)$ & $0(0.0 \%)$ & $1(3.6 \%)$ & \\
\hline anxiety/depression & excellent & $17(47.2 \%)$ & $3(37.5 \%)$ & $14(50.0 \%)$ & 0.599 \\
\hline & moderate & $18(50.0 \%)$ & $5(62.5 \%)$ & $13(46.4 \%)$ & \\
\hline & low & $1(2.8 \%)$ & $0(0.0 \%)$ & $1(3.6 \%)$ & \\
\hline$E Q-5 D D 360$ & & & & & \\
\hline$\%$ General QoL & & $63(40 ; 88)$ & $60(40 ; 85)$ & $67(44 ; 88)$ & 0.870 \\
\hline mobility & excellent & $8(23.5 \%)$ & $4(33.3 \%)$ & $4(18.2 \%)$ & 0.327 \\
\hline & moderate & $26(76.5 \%)$ & $8(66.7 \%)$ & $18(81.8 \%)$ & \\
\hline self-care & excellent & $24(70.6 \%)$ & $10(83.3 \%)$ & $14(63.6 \%)$ & 0.366 \\
\hline & moderate & $9(26.5 \%)$ & $2(16.7 \%)$ & $7(31.8 \%)$ & \\
\hline & low & $1(2.9 \%)$ & $0(0.0 \%)$ & $1(4.5 \%)$ & \\
\hline usual activities & excellent & $12(35.3 \%)$ & $6(50.0 \%)$ & $6(27.3 \%)$ & 0.303 \\
\hline & moderate & $21(61.8 \%)$ & $6(50.0 \%)$ & $15(68.2 \%)$ & \\
\hline & low & $1(2.9 \%)$ & $0(0.0 \%)$ & $1(4.5 \%)$ & \\
\hline pain/discomfort & excellent & $12(35.3 \%)$ & $5(41.7 \%)$ & $7(31.8 \%)$ & 0.377 \\
\hline & moderate & $20(58.8 \%)$ & $7(58.3 \%)$ & $13(59.1 \%)$ & \\
\hline & low & $2(5.9 \%)$ & $0(0.0 \%)$ & $2(9.1 \%)$ & \\
\hline anxiety/depression & excellent & $23(67.6 \%)$ & $10(83.3 \%)$ & $13(59.1 \%)$ & $0.046^{*}$ \\
\hline & moderate & $10(29.4 \%)$ & $1(8.3 \%)$ & $9(40.9 \%)$ & \\
\hline & low & $1(2.9 \%)$ & $1(8.3 \%)$ & $0(0.0 \%)$ & \\
\hline
\end{tabular}

1 parameters were described by the absolute and relative frequencies for categorical variables and median supplemented by $5^{\text {th }}-95^{\text {th }}$ percentile range for quantitative variables

2 statistical significance between the groups was set up using the ML-chi square test for categorical variables or Mann-Whitney U test for quantitative variables; *statistically significant

SAVR - Surgical Aortic Valve Replacement; TF+TA TAVI - Transfemoral + Transapical Transcatheter Aortic Valve Implantation; QoL - quality of life; EQ-5D - European Quality of Life Questionnaire, NA - not applicable 
Table 2. Comparison of quality of life among patients treated with surgical (SAVR) and transcatheter (TAVI) aortic valve implantation up to 1 year of follow-up.

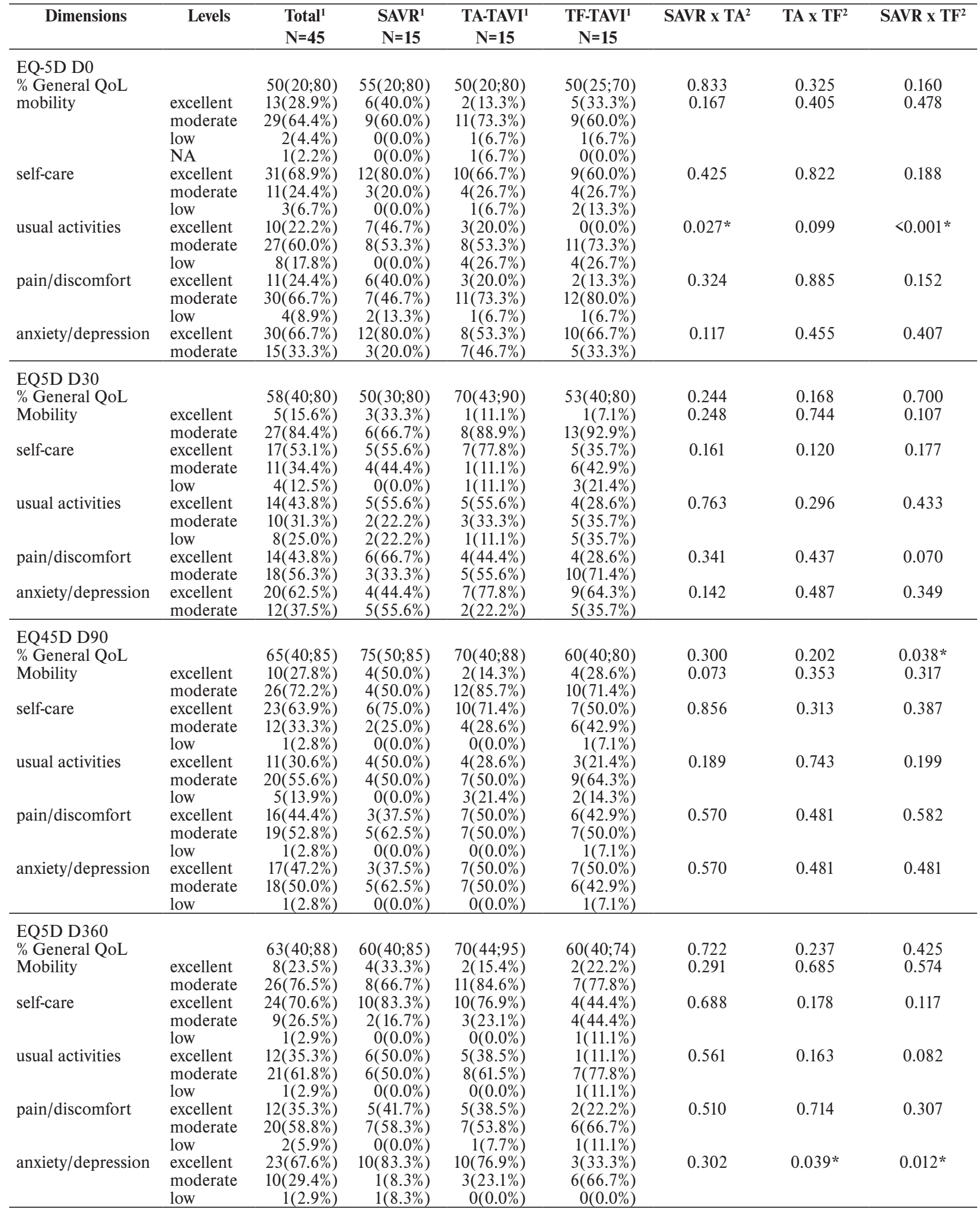

1 parameters were described by the absolute and relative frequencies for categorical variables and median supplemented by $5^{\text {th }}-95^{\text {th }}$ percentile range for quantitative variables

2 statistical significance between the groups was set up using the ML-chi square test for categorical variables or Mann-Whitney U test for quantitative variables; * statistically significant

SAVR - Surgical Aortic Valve Replacement; TF+TA TAVI - Transfemoral + Transapical Transcatheter Aortic Valve Implantation; QoL - quality of life; EQ-5D - European Quality of Life Questionnaire; NA - not applicable 


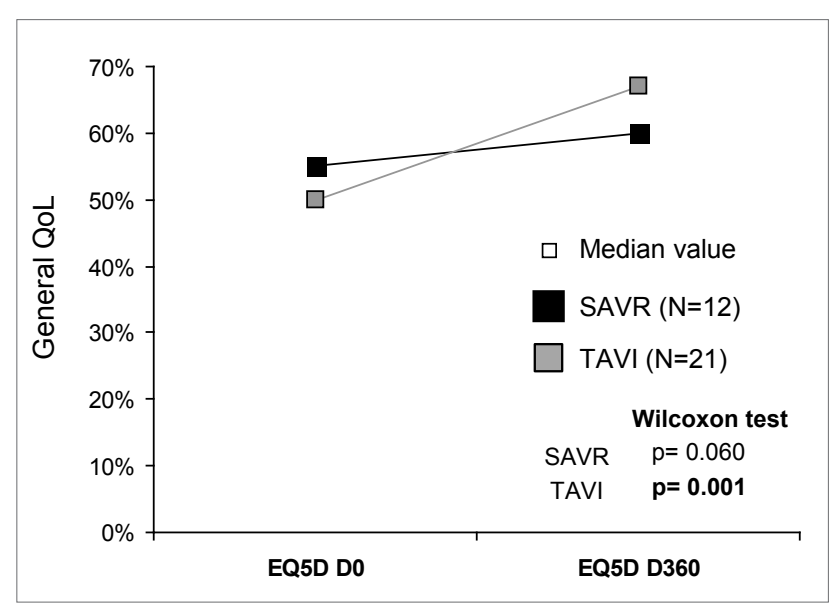

Fig. 1. Comparison of quality of life between baseline (D0) and 1-year (D360) follow-up within patients treated with surgical (SAVR) or transcatheter (TAVI) aortic valve implantation (data available from 33 patients).

substudy of the PARTNER trial ${ }^{12}$. The patients were randomized into TAVI using the Sapien valve or conservative treatment. TAVI patients improved significantly more than the conservative patients at 1 and 12 months, as assessed using the Kansas City Cardiomyopathy Questionnaire (KCCQ) and the SF-12 QoL questionnaires.

More information is available for the patients treated surgically. Sedryakan et al. confirmed that age was not a limiting factor for quality of life improvement after cardiac valve surgery ${ }^{13}$. Later on they found similar quality of life results in 73 prospectively evaluated patients after both mechanical and tissue valve implants at 18 months and after adjustment for age and several risk factors ${ }^{14}$. In contrast with these data we found only a positive trend in general QoL improvement in the "bioprosthesis" SAVR group at one year.

To the best of our knowledge a comparison between SAVR and TAVI, from the beginning of treatment through 1 yr. follow-up in the same Cardiac Center has never been published.

\section{Study limitation}

Due to its focus on the population of the Czech Republic, the study was limited in sample size and hence statistical power. This fact was taken into consideration during the interpretation and discussion of statistical results. The study was not randomized but observational, and was based on a multi-disciplinary heart-team decision. The standardized EQ-5D (three level) questionnaire that was used in the study prevented direct comparisons with results from other authors using different scoring systems (KCCQ, SF-36 or SF-12). The mental status of the patients was not assessed.

\section{CONCLUSIONS}

Transcatheter aortic valve implantation (TAVI), even at the beginning of the program, was shown to be associ- ated with excellent short- and middle-term results up to one year of follow-up. Relatively low mortality and excellent functional status of such patients has been well documented after both TAVI and surgical aortic valve replacement. At one year, the general quality of life of the surviving high-risk elderly patients was significantly improved after transcatheter aortic valve implantation and a positive trend was found in SAVR patients. We found no statistically significant differences between the quality of life of TAVI patients with regard to transfemoral or transapical approaches.

\section{ACKNOWLEDGEMENTS}

The study was supported by a grant of the IGA Ministry of Health of Czech Republic; No. NS/10643-3.

\section{CONFLICT OF INTEREST STATEMENT}

Author's conflict of interest disclosure: The authors stated that there are no conflicts of interest regarding the publication of this article.

\section{REFERENCES}

1. Iung B, Baron G, Butchart EG, Delahaye F, Gohlke-Bärwolf C, Levang OW, Tornos P, Vanoverschelde JL, Vermeer F, Boersma E, Ravaud $\mathrm{P}$, Vahanian A. A prospective survey of patients with valvular heart disease in Europe: The Euro Heart Survey on Valvular Heart Disease. Eur Heart J 2003;24(13):1231-43.

2. Nashef SA, Roques F, Michel P, Gauducheau E, Lemeshow S, Salamon R. European system for cardiac operative risk evaluation (EuroSCORE). Eur J Cardiothorac Surg 1999;16(1):9-13.

3. Leon MB, Smith CR, Mack M, Miller DC, Moses JW, Svensson LG, Tuzcu EM, Webb JG, Fontana GP, Makkar RR, Brown DL, Block PC, Guyton RA, Pichard AD, Bavaria JE, Herrmann HC, Douglas PS, Petersen JL, Akin JJ, Anderson WN, Wang D, Pocock S; PARTNER Trial Investigators. Transcatheter aortic-valve implantation for aortic stenosis in patients who cannot undergo surgery. N Engl J Med 2010;363(17):1597-607.

4. Johansson M, Nozohoor S, Kimblad PO, Harnek J, Olivecrona GK, Sjögren J. Transapical versus transfemoral aortic valve implantation: a comparison of survival and safety. Ann Thorac Surg 2011;91(1):57-63.

5. Rumsfeld JS. Valve Surgery in the Elderly: A Question of Quality (of Life)? J Am Coll Cardiol 2003;42(7):1215-17.

6. Vahanian A, Alfieri OR, Al-Attar N, Antunes M, Bax J, Cormier B, Cribier A, De Jaegere P, Fournial G, Kappetein AP, Kovac J, Ludgate S, Maisano F, Moat N, Mohr F, Nataf P, Piérard L, Pomar JL, Schofer J, Tornos P, Tuzcu M, van Hout B, Von Segesser LK, Walther T; European Association of Cardio-Thoracic Surgery; European Society of Cardiology; European Association of Percutaneous Cardiovascular Interventions. Transcatheter valve implantation for patients with aortic stenosis: a position statement from the European Association of CardioThoracic Surgery (EACTS) and the European Society of Cardiology (ESC), in collaboration with the European Association of Percutaneous Cardiovascular Interventions (EAPCI). Eur J Cardiothorac Surg 2008;34:1-8.

7. Nemec P, Ondrasek J, Malik P, Tretina M, Pokorny P, Poloczek M, Parenica J, Spinar J, Kala P. Comparison of the surgical and transcatheter aortic valve replacement in high-risk patients. Cor et Vasa 2012 (in press)

8. Rabin R, de Charro F. EQ-5D: a measure of health status from the EuroQol Group. Ann Med 2001;33(5):337-43.

9. Leon MB, Piazza N, Nikolsky E, Blackstone EH, Cutlip DE, Kappetein 
AP, Krucoff MW, Mack M, Mehran R, Miller C, Morel MA, Petersen J, Popma JJ, Takkenberg JJ, Vahanian A, van Es GA, Vranckx P, Webb JG, Windecker S, Serruys PW. Standardized endpoint definitions for Transcatheter Aortic Valve Implantation clinical trials: a consensus report from the Valve Academic Research Consortium. J Am Coll Cardiol 2011;57(3):253-69.

10. Georgiadou P, Kontodima P, Sbarouni E, Karavolias GK, Smirli A, Xanthos T, Troupis T, Khouri M, Papadimitriou L, Voudris V. Longterm Quality of Life Improvement After Transcatheter Aortic Valve Implantation. American Heart Journal 2011;162(2):232-7.

11. Bekeredjian R, Krumsdorf U, Chorianopoulos E, Kallenbach K, Karck M, Katus HA, Rottbauer W. Usefulness of percutaneous aortic valve implantation to improve quality of life in patients $>80$ years of age. Am J Cardiol 2010;106(12):1777-81
12. Reynolds MR, Magnuson EA, Lei Y, Leon MB, Smith CR, Svensson LG, Webb JG, Babaliaros VC, Bowers BS, Fearon WF, Herrmann HC, Kapadia S, Kodali SK, Makkar RR, Pichard AD, Cohen DJ for the Placement of Aortic Transcatheter Valves (PARTNER). Health-related quality of life after transcatheter aortic valve replacement in inoperable patients with severe aortic stenosis. Circulation 2011;124:1964-72.

13. Sedrakyan A, Vaccarino V, Paltiel AD, Elefteriades JA, Mattera JA, Sarah A. Roumanis SA, Zhenqiu Lin Z, Krumholz HM. Age does not limit quality of life improvement in cardiac valve surgery. J Am Coll Cardiol 2003;42:1208-14.

14. Sedrakyan A, Hebert P, Vaccarino V, Paltiel AD, Elefteriades JA, Mattera J, Lin Z, Roumanis SA, Krumholz HM. Quality of life after aortic valve replacement with tissue and mechanical implants. J Thorac Cardiovasc Surg 2004;128:266-72. 